\title{
ESCASSEZ \& EFICIÊNCIA AMBIENTAIS: UMA NOVA PERSPECTIVA NAS RELAÇÕES INTERNACIONAIS
}

\section{ENVIRONMENTAL SCARCITY \& EFFICIENCY: A NEW PERSPECTIVE IN INTERNATIONAL RELATIONS}

\author{
RAFAEL JOSÉ NADIM DE LAZARI \\ Universidade de Marília - UNIMAR \\ (Brasil) \\ prof.rafaeldelazari@hotmail.com \\ RICARDO PINHA ALONSO \\ Universidade de Marília - UNIMAR \\ (Brasil) \\ ripla1@gmail.com \\ MARCELO MAZIN \\ Universidade de Marília - UNIMAR \\ (Brasil) \\ marcelomazin0777@gmail.com
}

Fecha de recepción: 23 de febrero de 2021 / Fecha de aceptación: 16 de abril de 2021

RESUMO: A proposta do artigo é expor o binômio escassez \& eficiência em uma abordagem ambiental, na perspectiva das relações internacionais. Atualmente, quando se traz à luz a temática sustentabilidade ambiental, em âmbito global, não se pode olvidar de trazer à baila realidades importantes do 
século XXI. Essas realidades são representadas pelo processo de globalização que, embora possua um forte viés financeiro, por sua vez envolve uma multiplicidade de fatores sociais, culturais, jurídicos, econômicos, tecnológicos etc. Nesse diapasão, também é necessário lembrar que no plano internacional a sustentabilidade ambiental, quando ligada à escassez e eficiência, remete a questões de soberania estatal e, consequentemente, ao recente fenômeno de relativização da soberania - um importante vértice da crise do Estado nacional. De forma sobremaneira sintética, a dinâmica que envolve a escassez e eficiência ambientais, no palco das relações internacionais, traz ínsito o questionamento acerca de sua razoabilidade em vista do imenso custo social, sob os auspícios da comunidade internacional, para se manter o ciclo contínuo de crescimento do modelo econômico concentrado e acumulativo. Com vistas a alcançar o objetivo pretendido utilizou-se de pesquisas bibliográficas baseadas em obras correlatas, trabalhos científicos, legislações e doutrinas especializadas.

RESUM: El propòsit de l'article és exposar el binomi escassetat \& eficiència en un enfocament mediambiental, des de la perspectiva de les relacions internacionals. En l'actualitat, quan el tema de la sostenibilitat mediambiental es posa de manifest a escala mundial, no podem oblidar-nos de plantejar realitats importants del segle XXI. Aquestes realitats estan representades pel procés de globalització que, encara que té un fort biaix financer, al seu torn implica una multiplicitat de factors socials, culturals, legals, econòmics, tecnològics, etc. En aquest conjuntura, també cal recordar que, a escala internacional, la sostenibilitat mediambiental, quan està vinculada a l'escassetat i l'eficiència, es refereix a qüestions de sobirania estatal $i$, en conseqüència, al recent fenomen de relativització de la sobirania, un vèrtex important de la crisi de l'Estat nacional. D'una manera molt sintètica, la dinàmica que implica l'escassetat $\mathrm{i}$ l'eficiència mediambientals, a l'escenari de les relacions internacionals, planteja la qüestió de la seva equitat en vista de l'immens cost social, sota els auspicis de la comunitat internacional, de mantenir el cicle continu de creixement del model econòmic concentrat i acumulatiu. Per tal d'aconseguir l'objectiu previst, es va utilitzar la investigació bibliogràfica basada en obres relacionades, obres científiques, legislació i doctrines especialitzades. 
RESUMEN: El propósito del artículo es exponer el binomio escasez \& eficiencia en un enfoque ambiental, desde la perspectiva de las relaciones internacionales. En la actualidad, cuando se plantea el tema de la sostenibilidad ambiental a nivel mundial, no se puede olvidar traer a colación importantes realidades del siglo XXI. Estas realidades están representadas por el proceso de globalización, que si bien tiene un fuerte sesgo financiero, implica a su vez una multiplicidad de factores sociales, culturales, jurídicos, económicos, tecnológicos, etc. En este diapasón, también es necesario recordar que, en el ámbito internacional, la sostenibilidad ambiental, al estar vinculada a la escasez y a la eficiencia, remite a cuestiones de soberanía estatal y, en consecuencia, al reciente fenómeno de relativización de la soberanía, vértice importante de la crisis del Estado nacional. De manera muy sintética, la dinámica que involucra la escasez y la eficiencia ambiental, en el escenario de las relaciones internacionales, plantea la pregunta sobre su razonabilidad en vista del inmenso costo social, bajo el auspicio de la comunidad internacional, para mantener el ciclo continuo de crecimiento del modelo económico concentrado y acumulativo. Para alcanzar el objetivo previsto, se recurrió a la investigación bibliográfica basada en trabajos relacionados, obras científicas, legislación y doctrinas especializadas.

ABSTRACT: The purpose of the article is to expose the scarcity \& efficiency binomial in an environmental approach, from the perspective of international relations. Nowadays, when the theme of environmental sustainability is brought to light on a global level, one cannot forget to bring up important realities of the 21 st century. These realities are represented by the globalization process, which, although it has a strong financial bias, in turn involves a multiplicity of social, cultural, legal, economic, technological factors etc. In this tuning fork, it is also necessary to remember that, at the international level, environmental sustainability, when linked to scarcity and efficiency, refers to issues of state sovereignty and, consequently, to the recent phenomenon of relativization of sovereignty - an important vertex of the crisis of the national state. In a very synthetic way, the dynamics that involve environmental scarcity and efficiency, on the stage of international relations, raises the question about its reasonableness in view of the immense social cost, under the auspices of the 
international community, to maintain the continuous cycle of growth of the concentrated and cumulative economic model. In order to achieve the intended objective, bibliographic research based on related works, scientific works, legislation and specialized doctrines were used.

PALAVRAS-CHAVE: Escassez - Eficiência - Meio ambiente.

PARAULES CLAU: Escassetat - Eficiència - Medi ambient.

PALABRAS CLAVE: Escasez - Eficiencia - Medio ambiente.

KEYWORDS: Scarcity - Efficiency - Environment.

SUMÁRIO: Introdução. 1. A dinâmica evolutiva da escassez e eficiência no cenário internacional. 2. O axioma escassez na perspectiva da reserva do possível. 3. A percepção da escassez ambiental no plano nacional e internacional. 4. A escassez e a eficiência vistas como um vértice da crise do Estado nacional. Conclusão. Referências.

\section{INTRODUÇÃO}

A escassez, bem como a eficiência, são terminologias que sofreram uma consistente adição de valor ao longo dos séculos, desde as bases do Estado soberano até chegar aos dias atuais com profundas modificações de significado e valor. Entretanto, o ponto central é outro: escassez e eficiência, quando conectadas ao meio ambiente, adquirem significação e dinâmica inteiramente novas.

A abordagem do tema supracitado arrasta consigo uma enorme carga de transdisciplinariedade, pois envolve aspectos da macroeconomia, do direito constitucional, do direito internacional, ambiental etc. Assim, vêm à tona paradigmas que remetem aos idos de 1972, momento marcado pela Conferência de Estocolmo, com intensos debates em âmbito mundial que colaboraram na formação dos atuais modelos de sustentabilidade.

Esse consistente ganho de conteúdo e valor relativo ao conceito de escassez de recursos ambientais (e, consequentemente, eficiência na gestão desses recursos), no século XXI converteu-se em um ponto de inflexão para a 
soberania estatal - assunto retomado ao longo do artigo. Todavia, a dinâmica que envolve a escassez e a eficiência, quando observada pela perspectiva do ecocentrismo (ou matriz biocêntrica), permite constatar a existência concreta de um dos vértices de poder responsável pelo processo de relativização da soberania estatal responsável pela crise do Estado nacional.

Contudo, a escassez nunca esteve tão ligada ao meio ambiente, assim como a eficiência também nunca se aproximou tanto da gestão sustentável dos recursos ambientais. É justamente dentro dessa realidade de escassez que se propõe uma abordagem global do tema, em face das relações internacionais.

Ao final desse introito, cabe destacar que o desenvolvimento econômico não pode ser coibido totalmente pela proteção ambiental. No entanto, é imperativo que se pense em planos superiores de solidariedade e razoabilidade frente ao enorme "arrasto" socioambiental que implica a continuidade do modelo de crescimento a qualquer custo.

\section{A DINÂMICA EVOLUTIVA DA ESCASSEZ E EFICIÊNCIA NO CENÁRIO INTERNACIONAL}

Inicialmente, antes de adentrar propriamente em questões que envolvem as relações internacionais afetas à virtuosa pasta da sustentabilidade ambiental, necessário avançar em aspectos da economia mundial. Pois, não é possível tomar de assalto temáticas de sustentabilidade sem que, aprioristicamente, se considere, ao menos, uma breve trajetória da economia mundial.

Nesses termos, a dinâmica estabelecida entre a realidade de escassez e o compromisso com o resultado eficiente - ótimo - já era objeto de aprofundamento epistêmico por Adam Smith (1776), quando da publicação de "The wealth of nations", momento no qual ficou evidente que a ideia de uma "mão invisível" persuadiu profundamente o Estado liberal sobre os efeitos econômicos da ausência de recursos. Assim: "[...] a escassez necessariamente fará subir o preço" (SMITH, 1996, p. 251).

No entanto, é visível que nessa época a única face atribuída ao binômio escassez/eficiência era ligada ao pensamento maniqueísta - dualismo rico/pobre -, ou seja, voltado somente ao enriquecimento do Estado soberano, 
e este, conforme Bodin (1576), na obra "Les six livres de la republique", era estruturado pela soberania absoluta e perpétua - em outros termos, a soberania exercida pelo Estado e para o Estado (BODIN, 2017, p. 88).

O conceito de escassez e eficiência foi evoluindo ao longo da história, e assim ocorreu com o surgimento Estado liberal e a economia clássica, quando a escassez era vista de forma singela como ausência de insumos de produção e a eficiência ligava-se apenas à capacidade de produção. Nesse contexto, a visão prospectiva de Smith (1776), já naquela época, atribuía efeito trágico às decisões governamentais sobre a camada social menos provida de recursos. Dessa forma, na "[...] estação de escassez, o alto preço dos cereais certamente prejudica os pobres" (SMITH, 1996, p. 266).

Dessa perspectiva evolutiva fica a lição de que, assim como a economia neoclássica, a soberania clássica transcendeu para a interdependência progressiva do Estado nacional (também, mostrou-se possível deduzir que, modernamente, não há economia que possa se distanciar dos preceitos que envolvem o binômio escassez e eficiência). Em outros termos, sem escassez não há economia e, por conseguinte, a eficiência se traduz na alocação de recursos finitos para atender demandas infinitas.

Com o crash, em 1929, ocorreu a passagem do Estado liberal para o Estado de bem-estar social, daí a revolução do pensamento keynesiano (CALIENDO, 2016, p. 201). Por outra via, com a evolução da percepção acerca do que era escasso e o aperfeiçoamento da noção de eficiência, adveio nas décadas seguintes a assunção do significado de direitos de terceira dimensão - direito ao meio ambiente saudável e ecologicamente equilibrado.

Ao se atribuir uma significação comum à escassez, disso decorrem grandes implicações, pois a escassez é um conceito consideravelmente amplo, de modo a se estender para além das questões de ordem imediata, v.g., como a redução de recursos financeiros pessoais ou problemas temporários. Com isso, pode-se progredir para questões maiores, da ordem de saúde pública, como é o caso da dramática ausência de vacinas e de seringas em quantidades suficientes para a recente pandemia mundial da Covid-19. 
Em outra abordagem, Shafir e Mullainathan (2016), em sua obra seminal "Escassez", ensinam que a situação nova do isolamento social progressivo é também uma forma de escassez, pois, nos dias atuais não é incomum encontrar muitas pessoas praticando atividades sozinhas, o que se reduz a uma forma de escassez social. Entretanto, é factível conceber que não existe um conceito preciso de escassez, mas essa visão generalista projeta 0 pensamento diretamente para algo intuitivo. Em outros termos, "por escassez, queremos dizer ter menos do que você acha que precisa" (SHAFIR; MULLAINATHAN, 2016, p. 16).

A lógica supracitada foi empregada na década de 1970: enquanto o industrialismo fordista-keynesiano já prenunciava sinais de exaustão, paralelamente, emergia uma poderosa força antagônica ao industrialismo no cenário internacional. Assim, fortalecia-se a ligação entre escassez e os recursos naturais e, por seu turno, a eficiência começava a se ligar a preceitos de uma - ainda incipiente - sustentabilidade (de modo que, com a primeira conferência das Nações Unidas sobre o Meio Ambiente na cidade de Estocolmo, em 1972, marcou-se o ingresso da sustentabilidade no cenário mundial).

Como corolário da célebre conferência, a concepção acerca do que era escasso e o que deveria ser concebido como eficiente adquiriram um valor inteiramente novo, pois, a partir desse marco, a escassez passou a ser relacionada ao meio ambiente - biosfera (ao passo que a ausência de eficiência passou a ser relacionada diretamente às externalidades negativas no meio ambiente e, com isso, o binômio começava a se tornar um grande fator de influência no palco das relações internacionais).

Conforme exposto acima, Shafir e Mullainathan (2016) demonstram que o núcleo do problema reside muito além da ausência de insumos para a consecução de determinado projeto ou objetivo. Pois, quando os termos escassez e eficiência estiverem ligados ao meio ambiente, seus efeitos são lançados extrafronteiras, transcendendo diferenças culturais, sociais e, até mesmo, ideológicas; essa dinâmica pode ser visualizada sob a forma de uma linha de interesses comuns que se projetam sobre a sociedade global. Nessa ótica, a ausência de recursos faz parte da realidade de diversas culturas, 
sistemas políticos e Estados, porém a todos é atribuída a mesma problemática, assim caracterizando-se a mesma escassez.

Poder-se-ia pensar em uma racionalidade comum que opera junto a esses diversos cenários, mas, ao que parece, a realidade de escassez nunca deixou de estar surpreendentemente presente em todos os aspectos da vida e, também, sobre a biosfera. Dito isso, a escassez é uma inafastável responsabilidade da sociedade internacional, pois, em ultima ratio, o meio ambiente equilibrado depende de recursos naturais escassos e o resultado eficiente do emprego desses recursos diz respeito à observância do direito intergeracional - típico direito de terceira dimensão - que busca assegurar padrões desejáveis de bem-estar social para as presentes e futuras gerações.

Com o neoliberalismo, o conceito de escassez e eficiência começou a interagir com um novo elemento - segundo François Chesnais (1998) -, chamado mundialização da economia (e, mais tarde, veio a se difundir como o processo de globalização dos mercados). Assim, a escassez ambiental e a eficiência ligadas à produção começaram a sofrer a influência das assimetrias da globalização (com isso, tornaram-se o gatilho do processo de interdependência entre Estados). Sem embargo, mais à frente, será demonstrado que os novos paradigmas de escassez e eficiência, enquanto ligados ao meio ambiente, tornam-se, em verdade, fatores de transformação da nova ordem internacional.

Em outras palavras, André Ramos Tavares destaca que o século XXI é marcado pela acelerada interdependência dos Estados, iniciada pelo aumento expressivo da internacionalização dos mercados financeiros. Porém "[...] esse fenômeno é associado, também, ao fluxo de capitais que podem, em pouco tempo, abandonar um país e, com isso prejudicar a sua saúde financeira. Isso já ocorreu como o México, com a Argentina, com o Brasil e com o Uruguai” (TAVARES, 2003, p. 374).

O mundo, ao adotar esse mecanismo de internacionalização - ou, segundo Chesnais (1998), mundialização -, se depara com o problema dos custos sociais das tomadas de decisões decorrentes do "choque" entre os interesses que prevalecem sobre outros menos representados. Por sua parte, esse choque repercute socialmente e, não raras vezes, de formas trágicas, v.g., ao ser negligenciado o combate à Aids, à fome e à violência brutal à pessoa 
humana na África Subsaariana. É que, mundialização - leia-se globalização "[...] é bem mais que uma simples discussão econômica. Ela diz respeito às formas de domínio social próprio de uma fase histórica tomada como tal, da qual não podemos saber nem quanto tempo durará, nem por qual caminho a humanidade dela sairá" (CHESNAIS, 1998, p. 193). Portanto, no século XXI o binômio escassez/eficiência (em vertente ambiental) sofre a influência e o impacto contundente dos fatores de crescimento concentrado e produção capitalista acumulativa em contraposição ao novo racionalismo de proteção ambiental - sustentabilidade intergeracional.

Atualmente, a interdependência nas relações internacionais não se restringe apenas ao aspecto financeiro, mas, mormente, sobre o esforço global pela sustentabilidade ambiental. A interdependência gera a necessidade da existência de organismos supranacionais que, por sua vez, não escapam ao ônus de promover ações impactantes para a prevalência do equilíbrio e razoabilidade no cenário global.

Como se está a tratar de recursos escassos, naturalmente, as decisões governamentais, corporativas ou afetas a organismos supranacionais, quando priorizam determinados segmentos econômicos/sociais, justamente em função da escassez de recursos, invariavelmente resultam em escolhas trágicas. Essas escolhas podem ser constatadas, v.g., no estabelecimento de prioridades da Organização Mundial de Saúde (OMS) no combate à Covid-19, medidas da Organização das Nações Unidas (ONU) sobre o aquecimento global ou ações voltadas a conter a depleção (perda) ambiental no planeta.

Todas essas ações ocasionam externalidades negativas e, sendo assim, resultam em custos sociais. Portanto, ao se tratar de recursos ambientais escassos - ligados à equidade - voltados a resultados eficientes - afetos à otimalidade -, seja em âmbito doméstico, micro e macroeconômico, há a interferência de uma gestão de prioridades que, necessariamente, implicam em custos sociais, muitas vezes elevados.

Amaral, em sua obra "Direito, escassez \& escolha", assevera que há o consenso "firmado de que há menos recursos do que o necessário para o atendimento das demandas e que a escassez não é acidental, mas essencial, toma vulto a alocação de recursos" (AMARAL, 2010, p. 81). Desse modo, 
essas decisões alocativas reduzem-se a escolhas trágicas em razão de que, ao final, representam a negação de direitos.

Em síntese sobremaneira sintética, para Matias, em sua obra " $A$ humanidade $e$ suas fronteiras", é possível deduzir que nos dias atuais essa dinâmica se encontra marcada por dois fatores. O primeiro deles se refere à consolidação da consciência coletiva da realidade de escassez de recursos no planeta (e, por sua vez, esse pensamento induz o surgimento de novos paradigmas de eficiência - ecoeficiência - acerca desses recursos). O segundo fator refere-se à consolidação das organizações supranacionais a ponto de que os "seus órgãos podem possuir autoridade independente e suas decisões obrigam os Estados membros sem que esses tenham de aprová-las" (MATIAS, 2005, p. 374).

Por fim, no que tange ao entendimento acerca do que é escasso (vital) e do que se concebe por ecoeficiência, são conceitos dinâmicos que variam no tempo. Assim, refletem as demandas realocadas em classes mais elevadas de prioridades pela sociedade mundial, à medida que essas demandas se aproximam dos imperativos existência (ou sobrevivência).

\section{O AXIOMA ESCASSEZ NA PERSPECTIVA DA RESERVA DO POSSÍVEL}

Cabe destacar que a compreensão do significado atribuído ao termo axioma é de fundamental importância para a intelecção texto. Segundo o Dicionário Michaelis, o termo trata de uma "proposição imediatamente evidente, que prescinde de comprovação por ser admitida como portadora de verdade universal" (MICHAELIS, 2021). É exatamente no sentido axiomático de verdade universal que deve ser empregado o significado de escassez, justamente porque é evidente que os recursos naturais não renováveis, embora até certo ponto recicláveis (e, mesmo, submetidos à máxima eficiência), são todos finitos... e escassos.

Como premissa inicial, a terminologia ecoeficiência emergiu recentemente, embora seus preceitos já estivessem na mesa de discussões desde 1972, momento da célebre Conferência de Estocolmo. Foi a partir do livro "Changing Course" (1992) que a terminologia se difundiu mundialmente. Ainda assim, 
essa é uma dinâmica nova - apenas recentemente implementada - pois, nos "choques" ocorridos, desde Estocolmo, entre os velhos paradigmas do crescimento a qualquer custo e a recém inserida proposta de sustentabilidade ambiental, obviamente têm prevalecido os primeiros - 0 avanço do crescimento como um bólido descontrolado. Inobstante, complementa Dias, em sua obra "Antropoceno": "Um mundo sobre o qual cada um impõe sua pegada ecológica, cada vez maior, não é sustentável” (DIAS, 2016, p. 43).

Entretanto, na linha de Oliveira, apesar da resistência oferecida pelos velhos modelos de crescimento, o novo paradigma de eficiência implica na redução progressiva no recrutamento de recursos escassos. Portanto, a dinamicidade inovadora da ecoeficiência reside, na essência, em um compromisso ético intergeracional no processo de extração, produção, comercialização, uso e reciclagem. Desta feita, introjeta a lógica de se produzir mais com menos "[...] pois se trata da realização e entrega destes produtos de forma a satisfazerem as necessidades dos seus clientes mantendo ou aumentando a capacidade que o ecossistema possui de absorver os aspectos ambientais relacionados a esta produção" (OLIVEIRA, 2007, p. 29).

Conforme mencionado, o assunto escassez (e seu contraponto eficiência) é uma proposta que vem sendo debatida desde o alvorecer da década de 1970, momento no qual o Clube de Roma ${ }^{1}$ apresentou o estudo chamado "Os limites do crescimento" ${ }^{2}$. Com efeito, existe escassez de todas as formas, como a falta de água potável, energia elétrica e, até mesmo, o tempo (que, por uma visão axiomática, também é escasso). Então, a escassez passou a ser considerada nos tribunais e, por essa via, a sociedade alemã tornou-se precursora de uma visão singular sobre a escassez dos recursos do Estado (assim, não tardou em perceber que todas as pessoas estão imersas num ambiente de escassez que, necessariamente, implica em decisões trágicas).

\footnotetext{
1 O Clube de Roma foi fundado em 1968 e é constituído por um grupo de pessoas, de conhecimentos e posições singulares, que se reúnem para debater e refletir acerca de um vasto apanhado de assuntos ligados à política, relações e economia internacionais, e, sobretudo, ao meio ambiente e desenvolvimento sustentável.

2 Os "Limites do crescimento" é uma obra escrita em 1972 que modelou as consequências do acelerado crescimento da população do planeta considerando os limitados recursos naturais disponíveis.
} 
As ações sob os auspícios do Estado são limitadas e induzem questionamentos sobre a reserva do possível - vorbehalt des möglichen -, isto é, um olhar não diretamente focado na capacidade financeira estatal, mas, mormente, sobre a razoabilidade desse custo (conforme, inclusive, decidiu a Corte Constitucional alemã - Bundesverfassungsgericht). Nesses termos, Alonso esclarece que, "se não há previsão legal ou se a despesa decorrente da implementação direta dos direitos sociais, sem intermediação do legislador, é desproporcional, em tese, é legitima a oposição de resistência com apoio na teoria da reserva do possível" (ALONSO, 2012, p. 146).

Todavia, Araújo visualiza que a reserva do possível pode implicar em limitação a determinados direitos fundamentais, pois "todos os direitos representam custos a serem suportados pelo Estado e, em última análise, pela sociedade. Diante da escassez dos recursos necessários a tornar os direitos efetivos, eles perdem o significado, não passam de promessas feitas em papel" (ARAÚJO, 2011, p. 449). Portanto, os direitos que envolvem a atividade econômica, a livre iniciativa, a livre concorrência e a própria soberania do Estado nacional, por meio dum raciocínio paralelo, estão sujeitos a limitações, tais como: (i) de recursos naturais não renováveis; (ii) limitações de razoabilidade; e (iii) limitações lógicas, pois o custo desses direitos representa, ao longo do tempo, o colapso do ecossistema terrestre.

A ótica empregada é baseada na ausência de razoabilidade do alto custo social provocado pelo crescimento sem responsabilidade ambiental a ser suportado pela comunidade internacional (daí o transporte de aspectos da reserva do possível para o campo da escassez ambiental). Nessa linha, o professor Tavares entende que o desenvolvimento econômico deve ser pautado pelo desenvolvimento sustentável, assim "nem o desenvolvimento há de ser impedido pela proteção ambiental, nem o meio ambiente poderá ser desconsiderado pelo desenvolvimento econômico" (TAVARES, 2003, p. 196). Desse modo, propõe-se estabelecer o desdobramento do fenômeno da reserva do possível em uma perspectiva de escassez ambiental (ou seja, sustenta-se uma ousada e heterodoxa simetria entre a reserva do possível e o custo social do desequilíbrio ambiental provocado pelas atividades ambientalmente insustentáveis). 
Com isso, sugere-se emprestar a lógica da reserva do possível a fim de ser reempregada na área ambiental. Com esse transplante de ideias aparentemente inconciliáveis - reserva do possível e escassez ambiental -, por meio de um raciocínio dedutivo é possível chegar à conclusão no sentido de que o processo de crescimento econômico age sob os auspícios do ecossistema do planeta (e, por via de consequência, não é razoável admitir o avanço da depleção ambiental desarrazoada de compromissos intergeracionais). Porém, existe o caminho do meio representado pelo ótimo do equilíbrio entre a atividade produtiva e o meio ambiente. Nessa via: "É justamente esse equilíbrio entre o crescimento e o capital que desafia o gestor a encontrar soluções técnicas criativas que permitam produzir causando o menor impacto ambiental e em condições que não afastem a competitividade do empreendimento" (GODOY, 2017, p. 163).

No entanto, se a sociedade insistir em agir guiada pela idée-force do homem econômico neoclássico, fatalmente suplantar-se-á a capacidade de recomposição da biosfera. Nessa vertente, as decisões trágicas decorrentes de ambos os raciocínios - jurídico (reserva do possível) e ambiental (matriz biocentrada) - serão consequências lógicas da ausência de razoabilidade. Nos termos do memorável cientista romeno Nicholas Georgescu-Roegen na obra "La bioeconomia", derivada de estudos da década de 1960, o consumo desarrazoado de recursos não renováveis gera depleção ambiental e a conversão desses para energia térmica, em caráter irrevogável. Significa que, "[...] então o resultado é um aumento da não energia, utilizável ou não disponível, e para tanto da escassez" (ROEGEN, 2006, p. 334). Em termos mais simples, Veiga complementa: "Pode-se dizer que o aumento de entropia corresponde à transformação de formas úteis de energia em formas que a humanidade não consegue utilizar" (VEIGA, 2005, p. 120).

Por sorte, atualmente, na sociedade internacional tem ganhado força a matriz de pensamento acerca do consumo racional de recursos ambientais escassos, de modo que essa matriz perpassa, invariavelmente, por uma racionalidade baseada fundamentalmente na sustentabilidade ambiental. Todavia, "o uso ótimo e o uso sustentável são categorias que atendem a critérios distintos, o da eficiência e o da equidade" (VEIGA, 2005, p. 165). 
Sachs, em sua obra "Desenvolvimento includente, sustentável sustentado", esclarece que o conceito de sustentabilidade evoluiu. Assim, "ela é baseada no duplo imperativo ético de solidariedade sincrônica com a geração atual e de solidariedade diacrônica com as gerações futuras" (SACHS, 2004, p. 15). Disso se extrai a expressiva dinâmica que envolve a nova roupagem atribuída ao binômio: escassez constante e ecoeficiência sustentável.

Com efeito, constatou-se a existência de um aspecto-chave acerca do viés de proteção ambiental. Na linha de Matias, esse aspecto pode ser expresso em função de um longo processo de amadurecimento que remete à década de 1960, período anterior à Conferência de Estocolmo (1972). Dessa forma "devemos ir além dos padrões de pensamento herdados de nossas experiências passadas" (MATIAS, 2005, p. 464). Esse processo foi o berço do biocentrismo, resultando numa matriz que, em sua época, lançou influências sobre os ordenamentos jurídicos nacional e estrangeiros. Entretanto, seus efeitos de proteção ambiental não se exauriram nos anos de 1960-1970; na verdade, protraíram-se no tempo e avançaram significativamente nas décadas subsequentes, a ponto de, atualmente, relativizar o conceito clássico de soberania, sendo um dos fatores da crise do Estado nacional.

A otimização da governança global na área ambiental e da proteção dos direitos humanos reflete diretamente os novos paradigmas da sociedade global, para lidar com a realidade de escassez ambiental e a consequente necessidade de eficiência econômica. Indo mais além, Ferrajoli atribui a vinda à tona desses novos paradigmas, em última análise, ao fortalecimento da autonomia dos direitos da pessoa humana. Assim: "[...] através da superação da própria forma de Estado nacional e através da reconstrução do direito internacional, fundamentado não mais sobre a soberania dos Estados, mas desta vez sobre as autonomias dos povos" (FERRAJOLI, 2002, p. 52).

A escassez de recursos naturais, evidenciada pelos novos paradigmas de ecoeficiência, trouxe uma significação inteiramente nova ao conceito de eficiência econômica. Pois, qualquer iniciativa voltada ao desenvolvimento econômico, seja ela por empresas transnacionais, organizações intergovernamentais ou supranacionais, passa primeiramente, conforme Elkington, pelo "raio X do meio ambiente" (ELKINGTON, 2012, p. 241). 
O mundo é pontuado por demandas infinitas - entretanto, é provido de recursos limitados. Assim, a ecoeficiência emerge, não apenas como uma terminologia factível de apropriação acadêmica, mas sim como uma ideia que vem evoluindo há cerca de sessenta anos. Desse modo, essa "eco diretiva" representa o zelo na manipulação dos preciosos e escassos recursos naturais e, mais ainda, pela gestão responsável e eficiente desses recursos em observância ao direito fundamental ao meio ambiente saudável e ecologicamente equilibrado dedicado como compromisso ético em face das presentes e futuras gerações.

Em suma, retomando a questão da reserva do possível, não é razoável admitir teses jurídicas que esvaziem os recursos estatais para atender a finalidades impraticáveis levando à insustentabilidade (colapso) da estrutura social por insuficiência de recursos. Da mesma forma, não é plausível (razoável) seja admitida a prevalência de formas anacrônicas de crescimento baseadas, prioritariamente, na concentração e no acúmulo de riquezas em detrimento do único suporte à vida conhecido: a biosfera terrestre.

À primeira vista, salta aos olhos a aparente inconciliabilidade entre institutos diversos - reserva do possível e sustentabilidade ambiental -, mas, em olhar mais detido, ao ser adotada a perspectiva da escassez, é possível estabelecerse uma ligação útil para explicar que em ambos os institutos a lógica da escassez é, surpreendentemente, a mesma e corresponde ao mesmo significado: insuficiência.

A reserva do possível se sustenta, justamente, na tônica da razoabilidade associada ao emprego dos recursos estatais escassos (e, pela mesma via, a sustentabilidade ambiental se fundamenta na escassez ambiental que, por sua vez, remete à gestão razoável da biosfera terrestre); portanto, não é plausível (razoável) a destruição de recursos essenciais e finitos para simplesmente atender a demandas infinitas e fugazes de um número limitado de pessoas (e, ainda assim, afetas a uma única geração).

\section{A PERCEPÇÃO dA ESCASSEZ AMBIENTAL NO PLANO NACIONAL E INTERNACIONAL}


A dinâmica da escassez orbita por variados cenários. Dessa maneira, não se supõe de forma diversa sua ocorrência nos âmbitos governamentais e jurídicos, pois, conforme Amaral (2010), em sua obra "Direito, escassez \& escolha", se os recursos são escassos, então se faz necessário que ocorram decisões alocativas de recursos. Consequentemente, cabe decidir a quem atender e quais critérios de seleção usar sob o manto de estudos dos prognósticos para maximização dos resultados (como forma de se prestar contas à sociedade acerca da razão pela qual preferiu-se priorizar uma demanda e não outra). Nesse diapasão, "imaginar que não haja escolhas trágicas, que não haja escassez, que o Estado possa sempre prover as necessidades nos parece ou uma questão de fé, [...] ou uma negação total aos direitos individuais" (AMARAL, 2010, p. 17).

A consciência da escassez dos recursos naturais fez o legislador constitucional brasileiro assumir a responsabilidade pela proteção ambiental, bem como seu caráter intergeracional. De sorte que, o avançado art. 225 da Constituição brasileira (CF/1988) expressa o compromisso com a proteção ambiental e o esforço pela conquista de um meio ambiente equilibrado:

Art. 225. Todos têm direito ao meio ambiente ecologicamente equilibrado, bem de uso comum do povo e essencial à sadia qualidade de vida, impondo ao Poder Público e à coletividade o dever de defendê-lo e preservá-lo para as presentes e futuras gerações. $\S 1^{\circ}$. Para assegurar a efetividade desse direito incumbe ao poder público: I - preservar e restaurar [...]

Lazari esclarece que a CF/1988 abordou, de forma paradigmática, o meio ambiente sopesando não apenas o aspecto econômico, mas, mormente, por meio dum viés protecionista como expressão do compromisso intergeracional de equilíbrio ambiental - direito humano fundamental de terceira dimensão pois, "até então, o que se tinha era uma mera perspectiva econômica do meio ambiente, o que continua existindo na atual Lei Fundamental, com a diferença que agora ela é acompanhada por uma perspectiva social do meio ambiente" (LAZARI, 2019, p. 1180-1181).

Nesse sentido, porém enfatizando o pensamento biocêntrico, ensina Oliveira: "[...] o ambiente é visto como um elemento essencial para a continuidade da 
vida em nosso planeta. Sem meio ambiente ecologicamente equilibrado, 0 próprio direito à vida sucumbiria" (OLIVEIRA, 2020, p. 370). Os efeitos dessa matriz axiomática de perpétua escassez ambiental e ecoeficiência econômica repercutem ao longo de toda a $\mathrm{CF} / 1988$, pois ao tratar da ordem econômica ficou claro que a racionalidade biocêntrica expande seus efeitos muito além do viés protetivo (desse modo, alçando a órbita da ordem econômica). Nesse diapasão: "[...] A Constituição brasileira de 1988 elegeu também outros fundamentos para a Ordem Econômica, tão relevantes quanto aqueles primeiramente apontados, como o postulado de defesa do meio ambiente" (DALLAZEN, 2008 p. 59). Essa virtuosidade expressa-se no art. 170 da CF/1988:

Art. 170. A ordem econômica, fundada na valorização do trabalho humano e na livre iniciativa, tem por fim assegurar a todos existência digna, conforme os ditames da justiça social, observados os seguintes princípios: [...] VI - defesa do meio ambiente, inclusive mediante tratamento diferenciado conforme o impacto ambiental dos produtos e serviços e de seus processos de elaboração e prestação.

Aduz-se, das tendências do direito constitucional ambiental (conforme se extrai de diversas Cartas Magnas de diferentes países), que a matriz biocêntrica está presente sob a forma de um novo paradigma de proteção global. Dessa maneira, essa matriz ocasiona, até mesmo, um redirecionamento dos sistemas fiscais por meio da extrafiscalidade verde, que nada mais é que a exação tributária com fins ambientais (assim, é possível constatar que esse novo paradigma é um critério globalizante). Nesses termos, constata-se "[...] 0 critério ambiental, sendo a epistemologia ambiental o ponto de partida nesse redirecionamento" (CAVALCANTE, 2012, p. 96). Com isso, a Constituição Italiana verte sua matriz ambiental sobre a atividade produtiva, pois, conforme ressaltado logo no início, a atividade econômica não pode ser dissociada da disciplina ambiental. Assim, a atividade produtiva abarca o conceito de sustentabilidade na Constituzione:

Art. 41 L'iniziativa economica privata è libera. Non può svolgersi in contrasto con l'utilità sociale 0 in modo da recare danno alla sicurezza, alla libertà, alla dignità 
umana. La legge determina i programmi e i controlli opportuni, perché l'attività economica pubblica e privata possa essere indirizzata e coordinata a fini social ${ }^{3}$.

É importante a lição extraída da Constituzione, em razão de que é justamente na atividade produtiva que decorre um dos mais acalorados debates acerca da escassez de recursos naturais e das falhas de eficiência na gestão desses recursos frente à atividade econômica. Muito embora esse viés de proteção esteja presente em muitas Constituições mundo afora, é marcante a preocupação com a responsabilidade ambiental da Constituição Argentina:

Artículo 41. Todos los habitantes gozan del derecho a un ambiente sano, equilibrado, apto para el desarrollo humano y para que las actividades productivas satisfagan las necesidades presentes sin comprometer las de las generaciones futuras; y tienen el deber de preservarlo. El daño ambiental generará prioritariamente la obligación de recomponer, según lo establezca la ley. Las autoridades proveerán a la protección de este derecho, a la utilización racional de los recursos naturales, a la preservación del patrimonio natural y cultural y de la diversidad biológica, y a la información y educación ambientales ${ }^{4}$.

Disso, advém um grande esforço no âmbito da nova ordem internacional no sentido de compatibilizar a otimalidade com a sustentabilidade. Em um arrazoado final, Matias explica que a nova ordem mundial se relaciona diretamente com a limitação da soberania dos Estados, desta feita, "com essa limitação voluntária eles objetivam maior eficiência na execução de suas tarefas e na resolução de seus problemas" (MATIAS, 2005, p. 433). A busca pelo equilíbrio ambiental como direito intergeracional é um problema planetário e, evidentemente, está na agenda de prioridades da sociedade internacional.

\footnotetext{
3 Art. 41. A iniciativa econômica privada é gratuita. Não pode ocorrer em conflito com a utilidade social ou de uma forma que possa prejudicar a segurança, a liberdade, a dignidade humana. A lei determina os programas e controles adequados, para que a atividade econômica pública e privada possa ser dirigida e coordenada para fins sociais.

${ }_{4}^{4}$ Artigo 41. Todos os habitantes têm direito a um meio ambiente saudável e equilibrado, adequado ao desenvolvimento humano e às atividades produtivas que satisfaçam as necessidades presentes sem comprometer as das gerações futuras; e eles têm o dever de preservá-lo. O dano ambiental vai gerar prioritariamente a obrigação de reconstrução, conforme estabelecido em lei. As autoridades providenciarão a proteção desse direito, o uso racional dos recursos naturais, a preservação do patrimônio natural e cultural e a diversidade biológica, e a informação e educação ambiental.
} 


\section{A ESCASSEZ E A EFICIÊNCIA VISTAS COMO UM VÉRTICE DA CRISE DO ESTADO NACIONAL}

Foi ressaltando que, por volta de 1970 , emergiu a preocupação com a atividade produtiva causadora de desequilíbrio entrópico ${ }^{5}$ em função do adiantado processo de depleção ambiental. Georgescu-Roegen (2006), ao visualizar a dimensão do risco entrópico, lançou ao mundo, nos idos de 1970, um alerta de perigo ambiental baseado em estudos sobre a segunda lei termodinâmica - a entropia. Naquela época, seu pensamento já coadunava com a primeira conferência das Nações Unidas sobre o Meio Ambiente Humano, também chamada Conferência de Estocolmo (1972).

No entanto, o alerta de Georgescu, apesar de ser baseado num projeto de vanguarda (conhecido como programa bioeconômico mínimo), não obteve adesão social satisfatória. Embora à frente de seu tempo (e... talvez por essa exata razão), seus estudos de bioeconomia foram colocados literalmente no ostracismo. Esse fato histórico da literatura científica ocorreu em razão da prevalência do, ainda vigoroso, pensamento industrial-desenvolvimentista. Entretanto, a partir da década de 1990 seus estudos sobre a bioeconomia têm sido seriamente resgatados no segmento científico.

Atualmente, o mundo encontra-se em meio a uma prenunciada realidade de escassez progressiva de recursos naturais. Kate Raworth, na obra "Economia donut", enfatiza que a escassez não é um conceito tão indefinido, pois "em todo o mundo, o uso da água doce mais que triplicou, o uso de energia quadriplicou e o uso de fertilizantes mais que decuplicou" (RAWORTH, 2019, p. 56). Consequentemente, isso implica na transição do conceito de eficiência para ecoeficiência. Nessa esteira, Freitas, na obra "Sustentabilidade", destaca que "parece irrefutável, nessa altura dos acontecimentos que apenas a sustentabilidade modelará um desenvolvimento aceitável" (FREITAS, 2012, p. 78).

Em consonância com essa matriz de sustentabilidade, no presente, encontrase mais consolidado o posicionamento dos organismos transnacionais,

\footnotetext{
${ }^{5}$ Efeito do impacto ambiental provocado pela ação do homem. Em termos científicos a entropia corresponde à segunda lei da termodinâmica que mede o grau de aleatoriedade ou desordem em um sistema físico. Em termos mais simples, quer dizer a conversão de recursos naturais em energia térmica, porém, em caráter irrevogável.
} 
supranacionais e da comunidade internacional a respeito da necessidade de mudança de paradigmas alinhados ao desenvolvimento sustentável. É que "esse desenvolvimento se justifica na medida em que ele aumenta a garantia para os indivíduos" (MATIAS, 2005, p. 505). Nessa vertente, concentrando-se esforços no abandono do crescimento quantitativo, de modo a priorizar o qualitativo (SACHS, 2004, p. 13). Trata-se de uma forma viável de lidar com o axioma da escassez e se efetuar a verdadeira substituição por um novo paradigma eficiente de desenvolvimento econômico (baseado na ecocentrismo).

Aliado a isso, o pensamento biocentrado tem sido considerado um fator pósmoderno de interferência na soberania estatal. Mas, para melhor compreensão, necessário retroceder às bases do Estado nacional. Dessa forma, sustenta-se que a soberania possui um caráter dinâmico, constatado ao longo da história pela progressiva diluição do poder estatal - ou seja, quando da sistematização da soberania por Bodin (1576), enxergava-se o poder estatal como absoluto e perpétuo: "[...] a soberania dada a um Príncipe sob encargos e condições, não é propriamente soberania" (BODIN, 2017, p. 97). Isso identificava o forte viés absolutista que permeava as origens do Estado moderno. Entretanto, iniciou-se o processo de diluição com Jean-Jacques Rousseau (1762), com a célebre obra "Du contract social", ao estabelecer as bases do Estado moderno, em que também se eternizou um alerta: "Quando o nó social começa a afrouxar-se e o Estado a enfraquecer, quando os interesses particulares começam a fazer-se sentir e as pequenas sociedades a prevalecer sobre a grande, o interesse comum perde-se e encontra opositores" (ROUSSEAU, 2007, p. 98).

Com isso, Rousseau (1762) entendia que o enfraquecimento do "nó social" resulta em perda de unidade e, consequentemente, de poder. Mas, em pleno avançar do século XXI, o poder do Estado nacional encontra-se submetido a um processo abrasivo resultado do contato com novos fatores de poder igualmente consistentes, v.g., o fortalecimento dos direitos da pessoa humana reconhecidos mundialmente como direitos fundamentais.

Por via de consequência, o direito ao meio ambiente saudável e ecologicamente equilibrado tornou-se um direito fundamental da pessoa humana. Nessa direção, Borges entende ser o direito ao meio ambiente 
saudável e equilibrado "um direito intergeracional ou transgeracional, vale dizer, uma obrigação da sociedade presente para com a sociedade futura, uma promessa de cuidado para garantir vida digna às futuras gerações" (OLIVEIRA, 2020, p. 370).

Alonso bem observa que os direitos de terceira dimensão "voltam-se sim à preservação do ambiente saudável, da proteção do patrimônio comum dos povos e ultrapassam os limites territoriais do Estado para tutelar interesses da humanidade" (ALONSO, 2012, p. 27). Nessa esteira, um dos principais vértices de poder que desgasta o conceito de soberania estatal é a vinda à tona do novo paradigma de proteção ao meio ambiente; dessa forma, esse novo arquétipo tornou-se um consistente valor recepcionado pela comunidade internacional. Nada a obstar, "a universalização da proteção dos direitos humanos favoreceu, simultaneamente, o comprometimento dos Estados perante a comunidade internacional no que tange à proteção do meio ambiente e também à revisão do conceito de soberania" (COLOMBO; SPAREMBERGER, 2016, p. 230).

Henry Kissinger, na obra "Ordem internacional", complementa que "o sistema econômico internacional se tornou global, enquanto a estrutura política do mundo permaneceu baseada no conceito de Estado-nação" (KISSINGER, 2015 , p. 807). O problema da escassez está fortemente ligado às falhas de mercado; ademais, na linha de Veiga (2005), também está associado ao anacronismo dos modelos de produção e consumo persistentemente ineficientes, causadores de depleção ambiental, difusores de energia térmica e, por seu turno, indutores de desequilíbrio entrópico. Com isso, Elkington, em sua mais recente obra intitulada "Green swan" - coaduna com o estudo, que leva o mesmo nome, publicado pelo Bank for International Settlements no acender das luzes de 2020 -, enfatiza que "[...] é hora de declarar guerra a essas falhas do mercado e curar o capitalismo, restaurando a consciência em sua essência" (ELKINGTON, 2020, p. 207).

Vale a pena repisar: a interdependência dos Estados frente à nova ordem internacional está entrelaçada com os direitos da pessoa humana, sendo tal ideia respaldada pela Carta das Nações Unidas (1945), pela Declaração Universal dos Direitos do Homem (1948) e, mais recentemente, pela 
Declaração dos Direitos Humanos de Viena (1993). No entanto, a partir da Conferência de Estocolmo (1972), a proteção ao meio ambiente (em oposição ao sistema de produção acumulativa) é alçada ao patamar de direito fundamental do homem - e, por via de consequência, é fácil concluir que nessa "fórmula" está contido o axioma da escassez de recursos naturais. Nesse paradigma de proteção, também está contida a imperativa necessidade de adoção de modelos eficientes capazes de interagir com o atual paradigma de proteção, preservação, recomposição e reconstituição ambientais.

Em suma, a interdependência dos Estados e o fortalecimento da supranacionalidade no direito internacional (associados, é claro, ao novo paradigma de proteção ambiental biocentrado) condensaram-se em um dos vértices de poder responsáveis pela crise do Estado nacional. Nesses termos, Sáchica: "Nação, Estado e soberania são ideias em crise, transbordadas pelas aceleradas mudanças do século XX. A essas mudanças respondem os novos ordenamentos jurídicos e os conceitos de interdependência, região e comunidade" (SÁCHICA, 1985, p. 10). Por um prisma das relações internacionais, o binômio escassez/eficiência é um problema global e precisa ser gerido em sede de inter-relação e supranacionalidade. Por essa via, Kissinger, na obra "Diplomacy", assevera que "a economia mundial opera simultaneamente em todos os continentes. Surgiram várias questões que só se podem tratar em base mundial, como proliferação nuclear, meio ambiente, explosão populacional e interdependência econômica" (KISSINGER, 2012, p. 21-22).

Em síntese, a escassez de recursos naturais e a imperativa necessidade de gestão eficiente desses recursos apresentam-se como uma realidade surpreendentemente presente. Apesar dessa informação, em meio à comunidade internacional ainda se revela, paradoxalmente, que a insistência em modelos econômicos ambientalmente insustentáveis confirma a procedência da tese da fatalidade entrópica ${ }^{6}$ de Georgescu-Roegen (2006).

\footnotetext{
${ }^{6}$ Em pesquisas realizadas sobre o comportamento do consumidor (1935-1973) surge a tese da fatalidade entrópica resultante dos estudos do cientista romeno Nicholas Georgescu-Roegen. Segundo o autor, tal fatalidade é uma consequência natural do atual modelo de produção e consumo da economia mundial. Em outras palavras, o colapso do ecossistema terrestre.
} 
A opção dos Estados pelo modelo de produção e consumismo infinitos, baseado em recursos ambientais limitados, sintetiza o significado de uma legítima "escolha trágica". No entanto, o surgimento de uma nova racionalidade baseada na real percepção do significado de escassez e eficiência ambientais servem, não apenas, para acelerar o franco processo de diluição da soberania do Estado nacional, mas, principalmente, para Ihe conferir um novo contorno de responsabilidades frente à comunidade internacional. Nessa linha, o eventual surgimento de um novo contrato social (em função da crise do Estado nacional) pode, até mesmo, ser catalisado parcialmente pelo fortalecimento e conscientização mundial acerca da necessidade de se fazer valer o direito fundamental de proteção ao meio ambiente.

\section{CONCLUSÃO}

Foi dito que a dinamicidade integra o espírito das terminologias escassez e eficiência. Séculos se passaram e esse binômio nunca parou de agregar significado e valor, na perspectiva evolutiva da sustentabilidade ambiental. Essa característica dinâmica da escassez e da eficiência não é inteiramente boa, tampouco totalmente má, assim como a proteção ambiental nunca será inteiramente efetiva: é que, mesmo com a implementação de um programa bioeconômico mínimo, ainda assim continuará a existir entropia e geração de energia térmica (porém, ao que parece, em níveis mais sustentáveis).

Buscou-se demonstrar que a percepção da escassez de recursos ambientais e a eficiência ou otimalidade na utilização desses ativos ambientais estão ligadas à consolidação dos novos paradigmas de proteção ambiental e desenvolvimento sustentável. Essa dinâmica evolutiva serve de referência para se atribuir uma significação atual aos termos escassez e eficiência (isto é, em suas compreensões ambientais).

O racionalismo de proteção ambiental ganha consistência a partir da memorável Conferência de Estocolmo, em 1972. Entretanto, os valores forjados na célebre Conferência se fundiram a outros que integram a Carta das Nações Unidas (1945), a Declaração Universal dos Direitos do Homem (1948) 
e a Declaração Universal dos Direitos Humanos de Viena (1993). Assim surgiram os atuais paradigmas de sustentabilidade ambientais.

Com base nesses novos valores, o direito ao meio ambiente saudável e equilibrado tornou-se um direito fundamental da pessoa humana e seu caráter intergeracional foi reconhecido globalmente. Ocorre que a sustentabilidade ambiental, evidentemente, está intimamente ligada à escassez dos recursos ambientais. Assim, a própria capacidade do ecossistema terrestre de suportar a depleção (perda) causada pelo processo de produção de riquezas, por si só, já traz ínsito o conceito de escassez. Por sua vez, a eficiência está igualmente ligada à sustentabilidade ambiental, à medida que esta depende de resultados eficientes para deles verter o próprio significado de sustentabilidade.

Em síntese, a sustentabilidade ambiental traduzida no direito intergeracional ao meio ambiente saudável e equilibrado, de fato, é um direito universal da pessoa humana e, por via de consequência, sua inobservância, inefetividade ou, mesmo, a própria inexistência desse direito universal transgeracional é capaz de diluir e relativizar o conceito de soberania do Estado nacional frente à ação da comunidade internacional. Ocorre que essa relativização da soberania em função da escassez e da eficiência ambientais é um dos vértices que conferem poder e legitimidade às organizações dotadas de supranacionalidade. De forma voluntária ou não consensual, pois, o Estado pós-moderno sofre o fenômeno de diluição da soberania a ponto de inspirar o surgimento de um novo contrato social e, mesmo, uma nova noção de soberania (a dimensão que tomará esse processo ainda é uma questão em aberto).

Em um pensamento final, a escassez ambiental é uma realidade incrivelmente presente e inerente ao próprio significado de sustentabilidade da vida, ao passo que a eficiência é uma inafastável condição para a mantença do equilíbrio do ecossistema do planeta.

\section{REFERÊNCIAS}

ALONSO, Ricardo Pinha. Os direitos fundamentais sociais e o controle judicial das políticas publicas. PUC/SP, 2012. Disponível em: 
https://tede2.pucsp.br/bitstream/handle/6019/1/Ricardo\%20Pinha\%20Alonso.pd f. Acesso em: 3 jan. 2021.

AMARAL, Gustavo. Direito, escassez \& escolha: critérios jurídicos para lidar com a escassez de recursos e as decisões trágicas. 2. ed. Rio de Janeiro: Lumen Juris, 2010.

ARGENTINA. Constitución de la Nación Argentina. Editorial Universitário de Buenos Aires, 2004.

ARAÚJO, Kátia Patrícia de. Reserva do possível: os direitos fundamentais frente a escassez de recursos. Revista Acadêmica, vol. 83, 2011, p. 423/470.

BODIN, Jean. Les six livres de la République (French Edition). Éditions Myriel. Edição do Kindle, 2017.

BRASIL. [Constituição (1988)]. Constituição da República Federativa do Brasil. Obra coletiva de autoria da editora saraiva com colaboração de Antônio Luiz de Toledo Pinto et al. 37. ed. atual. e ampl. São Paulo: Saraiva, 2005.

CALIENDO, Paulo. Tributação e ordem econômica: os tributos podem ser utilizados como instrumentos de indução econômica? Rev. direitos fundam. democ., v. 20, n. 20, jul./dez. 2016, p. 193-234.

CAVALCANTE, Denise Lucena. Novos horizontes da tributação: um diálogo luso-brasileiro: Sustentabilidade financeira em prol da sustentabilidade ambiental. Coimbra: Almedina, 2012.

CHESNAIS, François. Mundialização do capital, regime de acumulação predominantemente financeira e programa de ruptura com o neoliberalismo. Revista Redes, Santa Cruz do Sul, v. 3, n. 1, 1998, p. 185/212.

COLOMBO, Silvana; SPAREMBERGER, Raquel Fabiana Lopez. A relativização do conceito de soberania como condição para proteção do direito fundamental ao meio ambiente. Revista da USP Direito, Estado e Sociedade, n. 49,2016 , p. $208 / 233$.

DALLAZEN, Dalton Luiz; LIMA JÚNIOR, Joel Gonçalves de. Tributação e ordem econômica. Revista Argumentum. Marília/SP, ano 9, no 09, 2008, p. $39 / 60$.

DIAS, Genebaldo Freire. Antropoceno: iniciação à temática ambiental. São Paulo: Gaia, 2016.

ELKINGTON, John. Canibais com garfo e faca. São Paulo: M.Books do Brasil, 2012.

ELKINGTON, John. Gree Swan. Fast Company Press. New York: New York, 2020. 
FERRAJOLI, Luigi. A soberania no mundo moderno. São Paulo: Martins Fontes, 2002.

FREITAS, Juarez. Sustentabilidade: direito ao futuro. 2. ed. Belo Horizonte: Fórum, 2012.

GODOY, Sandro Marcos. O meio ambiente e a função socioambiental da empresa. Birigui/SP: Boreal, 2017.

HAWKING, Stephen. Brief answers to the big questions. Rio de Janeiro: Intrínseca, 2019.

ITÁLIA. Constituzione Italiana. Introduzionedi Giangiulio Ambrosini. Torino: Piccola Biblioteca Einaudi, 2005.

KISSINGER, Henry. Diplomacy. Edição do Kindle. São Paulo: Saraiva, 2012.

KISSINGER, Henry. Ordem internacional. Edição Kindle. Rio de Janeiro: Objetiva, 2015.

LAZARI, Rafael de. Manual de direito constitucional. 3. ed. Belo Horizonte: D’Plácido, 2019.

MADARIAGA, Francisco Javier González. Ecoeficiencia: propuesta de diseño para el mejorameinto ambiental. Guadalajara: Editorial Universitaria, 2013.

MATIAS, Eduardo Felipe Pérez. A humanidade e suas fronteiras: do Estado soberano à sociedade global. São Paulo: Paz e Terra, 2005.

MICHAELIS. Dicionário de língua portuguesa. Disponível em: https://michaelis.uol.com.br/moderno-portugues/busca/portugues-

brasileiro/axioma/. Acesso em: 12 jan. 2021.

OLIVEIRA, Emerson Ademir Borges de. A Constituição brasileira ao alcance de todos. Belo Horizonte, São Paulo: D'Plácido, 2020.

OLIVEIRA, Flávio. Ecoeficiência: a gestão do valor ambiental. EPSE Editora. Edição do Kindle, 2007.

RAWORTH, Kate. Economia donut: uma alternativa ao crescimento a qualquer custo. Rio de Janeiro: Zahar, 2019.

ROEGEN, Nicholas Georgescu. La bioeconomia. Spain: Montesinos, 2006.

ROUSSEAU, Jean-Jacques. O contrato social. Edição do Kindle. Porto Alegre: L\&PM Editores, 2007.

SÁCHICA, Luis Carlos. El ordenamiento juridico andino y su Tribunal de Justicia. In: El Tribunal de Justicia del Acuerdo de Cartagena. Montevidéu: BIDINTAL, 1985. p. 5-26. 
SACHS, Ignacy. Desenvolvimento includente, sustentável sustentado. Rio de Janeiro: Garamond, 2004.

SHAFIR, Eldar; MULLAINATHAN, Sendhil. Escassez. Kindle. Rio de Janeiro: Best Business, 2016.

SMITH, Adam. A riqueza das nações: investigação sobre sua natureza e suas causas. São Paulo: Nova Cultural, 1996.

TAVARES, André Ramos. Direito constitucional econômico. São Paulo: Editora Método, 2003.

VEIGA, José Eli. Desenvolvimento sustentável: o desafio do século XXI. Rio de Janeiro: Garamond, 2005. 